\title{
IMPLEMENTASI DAN EVALUASI MODUL PEMBELAJARAN ILMU PENDIDIKAN KEDOKTERAN UNTUK MAHASISWA KEDOKTERAN TAHAP PREKLINIK
}

\author{
Natalia Puspadewi, Elisabeth Rukmini \\ Medical Education Unit Fakultas Kedokteran Unika Atma Jaya
}

\begin{abstract}
Background: To keep up with current development in medicine, every doctor is demanded to be able to do continuing medical education (CME) after finishing their medical degree. However, health education institutions are responsible to make sure their graduates are able to do so by developing their self regulated learning (SRL) skills. Therefore, we developed a learning module that not only use adult learning approach but also maximizing the teachers' role in the teaching and learning process by using a programmatic assessment model.
\end{abstract}

Method: The learning activities mostly used SCL approach (62,7\%), and were comprised of 8 different learning method. The assessment activities were done by using a combination of assessment method to assess the student's cognitive, skills, and professional behavior. The student was also asked to do a self evaluation using reflective writing assignment, and each of the student also received 360 degree. Each student was assigned to 1 mentor to guide him/her throughout the course. Results: More than half of the students $(52,24 \%)$ claimed that they were 'forced' to take the course because they didn't get into their first choice elective block. However, at the end of the block, all of the students had a change of perspective and agreed that this block was interesting and useful for them.

Conclusion: The students are able to be independent if we, as teachers, maximized our role as facilitators and mentors, and give the students bigger autonomy in their study.

Keywords: self regulated learning, student centered learning, elective module

\section{ABSTRAK}

Latar belakang: Setiap dokter dituntut untuk mampu melakukan pendidikan dokter yang berkelanjutan (continuing medical education) agar dapat mengikuti perkembangan ilmu kedokteran. Hal tersebut merupakan tanggung jawab pribadi masing-masing dokter, akan tetapi institusi pendidikan kesehatan bertanggung jawab untuk memastikan agar lulusan dokter memiliki kemampuan self regulated learning agar dapat melaksanakan CME. Untuk itu, kami mengembangkan modul pembelajaran yang menggunakan pendekatan andragogik serta memaksimalkan peran dosen dalam proses pembelajaran melalui model programmatic.

Metode: Aktivitas pembelajaran yang digunakan sebagian besar adalah metode SCL (62,7\%) dan terdiri dari 8 metode pembelajaran. Aktivitas assessment menggunakan kombinasi beberapa metode assessment untuk menilai aspek kognitif, keterampilan, dan perilaku profesional. Tiap mahasiswa juga diminta untuk melakukan self evaluation melalui tulisan reflektif dan mendapat feedback 360 derajat. Masing-masing mahasiswa mendapatkan 1 orang mentor untuk membimbing mereka sepanjang blok. Evaluasi blok dilakukan melalui pengisian kuesioner yang dilakukan oleh mahasiswa di akhir blok.

Hasil: Lebih dari separuh mahasiswa (52,24\%) menyatakan bahwa awalnya mereka terpaksa untuk mengikuti blok ini karena pilihan pertama blok elektif mereka sudah penuh. Akan tetapi, diakhir blok, semua mahasiswa mengalami perubahan paradigm dan setuju bahwa blok ini merupakan blok yang menarik dan bermanfaat bagi mereka.

korespondensi: natalia_puspadewi@yahoo.com 
Kesimpulan: Mahasiswa dapat dilatih untuk lebih mandiri apabila mereka diberikan otonomi yang lebih besar dalam belajar serta didukung oleh dosen yang memaksimalkan peran sebagai fasilitator dan mentor.

Kata kunci: self regulated learning, student centered learning, modul blok elektif

\section{PENDAHULUAN}

Secara garis besar, pendidikan kedokteran di Indonesia terbagi menjadi 3 tahap, yaitu pendidikan sarjana kedokteran (tingkat preklinik), pendidikan profesi (tingkat klinik dan/atau spesialis/ subspesialis), dan pendidikan kedokteran yang berkelanjutan (continuing medical education/CME). ${ }^{1}$ Berbeda dengan pengembangan kompetensi sesuai standar nasional, ${ }^{2}$ yang merupakan tanggung jawab institusi pendidikan dokter, pendidikan kedokteran yang berkelanjutan pada dasarnya merupakan tanggung jawab pribadi masing-masing dokter setelah menuntaskan pendidikan mereka. Namun demikian, institusi pendidikan kedokteran wajib menanamkan sifat kemandirian dalam belajar pada setiap lulusannya karena hal tersebut merupakan salah satu kompetensi yang menjadi dasar dari kompetensi lainnya bersama-sama dengan kompetensi profesionalisme dan komunikasi efektif. ${ }^{2}$

Salah satu yang menunjang terjadinya CME adalah kemampuan untuk melakukan self regulated learning (SRL). ${ }^{3}$ Menurut Berkhout, et al., ${ }^{4}$ terdapat 4 hal yang mempengaruhi kemampuan SRL seseorang, yaitu: tujuan belajar, kesempatan melakukan SRL, tingkat otonomi saat belajar, serta hasil yang diharapkan. Usaha yang telah dilakukan untuk meningkatkan kemampuan SRL mahasiswa adalah dengan meningkatkan penggunaan metode pembelajaran yang berorientasi kepada mahasiswa/ student centered learning/SCL. Namun demikian, dari beberapa studi mengenai metode SCL yang ada, ${ }^{5-7}$ faktor budaya memiliki peranan yang sangat penting dalam efektivitas metode tersebut untuk menumbuhkan sikap SRL. Selain itu, peran aktif dosen dalam mendorong dan memotivasi mahasiswa untuk mandiri dalam belajar juga menjadi faktor penting dalam pembentukan sikap SRL mahasiswa.?
Hal-hal diatas mendorong dibentuknya sebuah modul pembelajaran yang tidak hanya menggunakan pendekatan adult learning, sebagai usaha menumbuhkan sikap SRL mahasiswa, tetapi juga memaksimalkan peran serta dosen di dalam proses pembelajaran. Blok Elektif Ilmu Pendidikan Kedokteran dalam metode pembelajarannya, dimaksudkan untuk memfasilitasi SRL mahasiswa melalui ilmu pendidikan kedokteran.

\section{METODE}

Blok Elektif Ilmu Pendidikan Kedokteran (IPK) merupakan salah satu dari empat modul blok elektif FK Unika Atma Jaya yang dilaksanakan pada awal semester 7 selama 5 minggu. Pemilihan blok elektif dilakukan secara bebas oleh mahasiswa tahun ke-4 dengan sistem kuota, yaitu blok elektif akan ditutup apabila mencapai jumlah mahasiswa tertentu sehingga mahasiswa yang belum terdaftar, diwajibkan memilih blok elektif lain yang masih belum memenuhi kuota.

Blok ini dirancang untuk mengajak mahasiswa mengenal berbagai aspek teoritis dan praktis dari proses pembelajaran ilmu kedokteran untuk kemudian diterapkan dalam kehidupan sehari-hari agar terbentuk sikap belajar sepanjang hayat. Sikap belajar sepanjang hayat penting untuk ditumbuhkan kepada masing-masing mahasiswa agar secara terus menerus sadar akan perkembangan dinamis ilmu kedokteran. Blok ini mencakup pemahaman belajar dan komunikasi secara personal maupun sosial, kepada komunitas ilmiah maupun kepada masyarakat. Blok ini bersifat integratif, berupaya untuk mewadahi aspek-aspek sosial dan analisisnya sehingga memberikan gambaran holistik bagi mahasiswa bahwa proses belajar (juga mengajar) adalah tindakan sosial. 
Dalam perencanaannya, Blok Elektif IPK dirancang dengan menggunakan model programmatic assessment dengan menitikberatkan pada pembelajaran yang bersifat andragogik. Terdapat 3 komponen utama yang menyusun blok ini, yaitu: aktivitas pembelajaran, aktivitas assessment, dan aktivitas pendukung.

\section{Aktivitas Pembelajaran}

Pemilihan aktivitas pembelajaran didasarkan atas kesesuaian metode pembelajaran dengan tingkat kompetensi yang diinginkan, yaitu mampu merancang desain pendidikan baik di tingkat komunitas, masyarakat secara individu, dan desain pembelajaran di tingkat klinik atau preklinik berdasarkan teori-teori terkait pendidikan dalam kerangka terbimbing. Rincian aktivitas pembelajaran yang digunakan dapat dilihat pada tabel 1 .

Tabel 1. Rancangan Aktivitas Pembelajaran Blok Elektif IPK

\begin{tabular}{|c|c|c|c|}
\hline \multirow{2}{*}{$\begin{array}{l}\text { Aktivitas } \\
\text { Pembelajaran }\end{array}$} & \multicolumn{2}{|c|}{$\begin{array}{l}\text { Jumlah Jam } \\
\text { Tatap Muka }\end{array}$} & \multirow[t]{2}{*}{ Keterangan } \\
\hline & Jam & $\%$ & \\
\hline Kuliah interaktif & 28 & 37,3 & $\begin{array}{l}\text { Pemberian kuliah dilakukan untuk memperkenalkan materi-materi } \\
\text { dasar yang wajib diketahui oleh mahasiswa. }\end{array}$ \\
\hline Open discussion & 19 & 25,3 & $\begin{array}{l}\text { Kegiatan ini dilakukan segera setelah pemberian kuliah. Mahasiswa } \\
\text { mendapatkan kesempatan untuk berdiskusi serta bertanya dan/atau } \\
\text { memberikan komentar mengenai hal-hal yang terkait dengan materi } \\
\text { kuliah yang baru disampaikan. Diskusi terbuka ini bertujuan untuk } \\
\text { memicu mahasiswa untuk berpikir kritis serta memperdalam topik } \\
\text { kuliah. }\end{array}$ \\
\hline Working Group & 12 & 16 & $\begin{array}{l}\text { Dalam sesi working group, mahasiswa diberikan kesempatan untuk } \\
\text { mengerjakan tugas-tugas blok dengan bimbingan staf pengajar. Staf } \\
\text { berada dalam ruang bersama para mahasiswa dalam kelompok. Sifat } \\
\text { bimbingan adalah incidental, yaitu staf hanya akan memberikan } \\
\text { bimbingan apabila mahasiswa meminta bantuan/bertanya pada sesi } \\
\text { working group. Seorang staf pengajar membimbing } 5 \text { kelompok ( } 26 \\
\text { orang). }\end{array}$ \\
\hline Video Teaching & 1 & 1,3 & Pembelajaran dengan menonton video \\
\hline Field Study & 5 & 6,7 & $\begin{array}{l}\text { Kunjungan ke klinik yang dikelola Yayasan Orang Tua Peduli, suatu } \\
\text { yayasan yang bergerak dalam edukasi pasien dan masyarakat sebagai } \\
\text { konsumen layanan kesehatan }\end{array}$ \\
\hline Workshop & 4 & 5,3 & $\begin{array}{l}\text { Bersifat hands on, terdiri dari sesi pemberian materi diikuti dengan } \\
\text { praktik langsung. }\end{array}$ \\
\hline Skills lab & 6 & 8 & - \\
\hline Elearning & $\sim$ & $\sim$ & $\begin{array}{l}\text { Materi-materi pendukung kuliah diunggah ke dalam e-learning FKUAJ } \\
\text { dan mahasiswa bebas untuk membaca dan mengunduh materi tersebut. } \\
\text { Pengumuman, pengumpulan tugas serta kuis dilakukan melalui } \\
\text { e-learning. }\end{array}$ \\
\hline Total & 75 & 100 & \\
\hline
\end{tabular}

\section{Aktivitas Assessment}

Assessment yang digunakan dalam Blok IPK FKUAJ terdiri dari beberapa macam, yaitu: ujian tertulis (berupa essai dan kuis), project based assessment, penulisan laporan, reflective writing, responsi skills lab, serta $360^{\circ}$ feedback.

Ujian tertulis dan penulisan laporan digunakan untuk menilai aspek kognitif serta ditujukan untuk 
mengevaluasi pemahaman mahasiswa mengenai materiblokyangtelah diberikan. Projectbasedassessment digunakan untuk melihat aplikasi pengetahuan yang dimiliki mahasiswa yang dituangkan dalam sebuah proyek yang siap guna. Salah satu contoh project based assessment yang dilakukan adalah membuat media edukasi personal sesuai dengan target audiens yang dituju. Ujian presentasi dan project based assessment dinilai oleh 2 orang penguji menggunakan rubrik yang disusun oleh pengampu topik terkait dan untuk memastikan reliabilitas nilai dari kedua penguji tersebut dilakukan uji inter-rater reliability. Apabila kesepakatan antar penguji kurang dari 90\%, kedua penguji meninjau kembali penilaian yang telah diberikan hingga tercapai kesepakatan.

Aspek keterampilan dinilai dari responsi skills lab. Reflective writing dapat digunakan untuk menilai aspek kognitif mahasiswa mengenai materi blok maupun pengertian mahasiswa terhadap aspek kognitif dari keterampilan yang diajarkan di blok, tergantung dari refleksi yang diangkat mahasiswa dalam tulisan mereka. Pemberian feedback dilakukan oleh beberapa pihak, yaitu dosen, mahasiswa, dan pasien simulasi menggunakan kuesioner Musick ${ }^{8}$. Feedback yang terkumpul kemudian dikompilasi serta dibahas oleh dosen mentor bersama-sama dengan mahasiswa (secara pribadi) pada sesi mentoring.

\section{Aktivitas Pendukung}

Jumlah mahasiswa yang mengikuti Blok Elektif IPK adalah sebanyak 52 orang. Mahasiswa kemudian dibagi menjadi 5 kelompok mentoring, masing-masing kelompok beranggotakan 10-11 orang untuk setiap dosen mentor. Mereka diwajibkan untuk bertemu dengan mentor mereka minimal 1 minggu sekali untuk membahas kemajuan belajar di blok maupun membicarakan mengenai kesulitan-kesulitan yang mungkin mereka temui pada saat belajar di blok. Seluruh mentor telah diberikan pengarahan sebelumnya oleh tim blok.

Pada akhir blok, setiap mahasiswa diminta untuk mengisi kuesioner evaluasi blok yang terdiri atas pertanyaan terbuka dan tertutup. Pengisian kuesioner dilakukan secara online melalui google form.

\section{HASIL DAN PEMBAHASAN}

Hal-hal yang dievaluasi dalam kuesioner evaluasi blok antara lain: alasan mahasiswa memilih Blok IPK, persepsi mereka terhadap pelaksanaan Blok IPK yang mencakup materi dan kemampuan pembawa materi di blok, serta saran bagi blok. Dari 52 mahasiswa yang mengambil blok elektif, 51 mahasiswa mengisi kuesioner evaluasi blok.

\section{a. Alasan memilih Blok IPK}

Hampir sebagian besar mahasiswa (52,24\%) mengakui bahwa pada awalnya mereka terpaksa memilih Blok IPK. Keterpaksaan tersebut terjadi akibat beberapa hal, antara lain: tidak mendapatkan blok yang diinginkan (34,4\%), tidak ada pilihan lain $(10,45 \%)$ dan menghindari blok tertentu $(7,47 \%)$. Namun demikian, ada juga mahasiswa yang memang memilih Blok IPK karena tertarik dengan materi yang ada di blok $(9,1 \%)$, tertarik dengan metode pembelajaran yang digunakan di Blok IPK $(1,7 \%)$, maupun tertarik akibat promosi blok yang baik $(1,1 \%)$.

Meskipun cukup banyak mahasiswa yang pada awalnya tidak tertarik untuk mengikuti blok ini, ternyata seiring dengan berjalannya blok, pandangan mereka berubah. Seluruh mahasiswa menyatakan bahwa Blok IPK merupakan blok yang menarik dan bermanfaat. Tidak ada respon yang menyatakan sebaliknya.

\section{b. Efektivitas metode pembelajaran yang digunakan dalam Blok IPK}

Dari seluruh metode pembelajaran yang digunakan di dalam Blok IPK, tidak ada metode pembelajaran yang dianggap tidak efektif oleh mahasiswa. Namun demikian, terdapat cukup banyak mahasiswa (26\%) yang menganggap bahwa metode open discussion kurang efektif apabila dibandingkan dengan metode pembelajaran lainnya. 


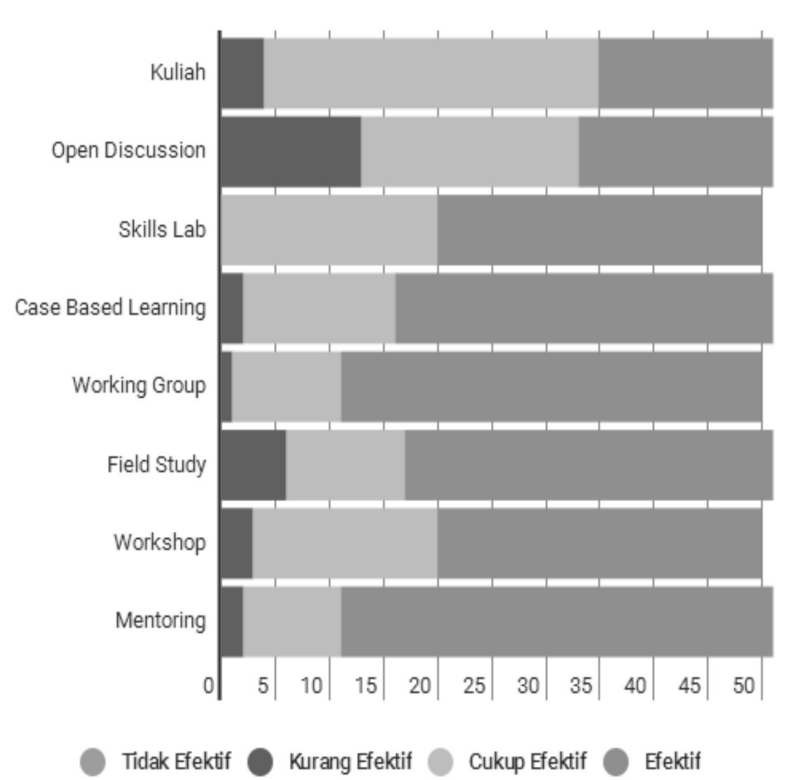

Gambar 1. Efektifitas Masing-Masing Metode Pembelajaran

\section{c. Manfaat mentoring}

Empat puluh sembilan dari 51 (96\%) mahasiswa menganggap bahwa kegiatan mentoring bermanfaat. Mereka kemudian diminta untuk menjelaskan mengapa mereka menganggap bahwa kegiatan mentoring tersebut bermanfaat melalui pertanyaan terbuka yang termasuk di dalam kuesioner.

Sebagian besar mahasiswa (55,9\%) menganggap bahwa kegiatan mentoring sangat bermanfaat sebagai wadah diskusi mengenai tugas-tugas yang ada di dalam blok serta memicu mereka untuk lebih aktif bertanya.

"Saya dapat bertanya mengenai hal-hal yang tidak saya mengerti tetapi tidak (saya tanyakan) di dalam kelas besar karena saya malu"

Manfaat lain yang mereka rasakan adalah di kegiatan mentoring, mereka dapat menyamakan persepsi mengenai bagaimana bentuk tugas yang diinginkan oleh tim blok, terutama karena tugastugas di Blok IPK tergolong 'baru' dan 'tidak biasa' bila dibandingkan dengan tugas-tugas di blok lain. Selain itu, kegiatan mentoring juga dianggap dapat meningkatkan motivasi mahasiswa dalam belajar dan mengerjakan tugas serta memfasilitasi terjadinya pemberian feedback oleh dosen kepada mahasiswa.
".... dan menjadi target tersendiri untuk menyelesaikan tugas karena tidak mau mengecewakan mentor"

Selain sisi akademik, kegiatan mentoring juga dianggap mampu membina hubungan yang lebih personal antara dosen dan mahasiswa. Mahasiswa merasa menjadi lebih dekat dengan dosen mentor mereka serta tidak merasakan adanya senioritas antara dosen dan mahasiswa dengan adanya kegiatan mentoring ini.

“... Dengan mentoring saya juga merasa menjadi lebih mengenal dosen dan tidak merasa adanya senioritas antara mahasiswa dan dosen."

Dua orang mahasiswa menganggap bahwa kegiatan mentoring tidak memiliki manfaat untuk mereka. Ketika ditanyakan lebih lanjut mengapa mereka berpendapat demikian, mereka menyatakan bahwa mereka kesulitan dalam mengatur jadwal dengan mentor mereka, terlebih karena kegiatan mentoring ini diwajibkan untuk dilaksanakan minimal 1 kali dalam 1 minggu.

Desain programmatic assessment yang digunakan di Blok IPK FKUAJ mengikuti model yang diajukan oleh van der Vleuten, et al. ${ }^{9}$ Di tahap pendidikan akademik (S1), terutama tingkat blok, rancangan programmatic assessment memiliki keterbatasan dalam pemilihan metode assessment. Metode assessment yang dapat digunakan di tahap pendidikan akademik pada umumnya menitikberatkan pada penguasaan keilmuan (aspek kognitif), sedangkan metode assessment untuk aspek keterampilan dan aspek perilaku sangat minim. Untuk aspek keterampilan, metode assessment yang digunakan di FKUAJ terbatas pada responsi skills lab (untuk tingkat blok). ${ }^{10}$ Metode Objective Structured Clinical Examination/OSCE pada umumnya tidak dilakukan di tingkat blok karena dianggap kurang efektif dan efisien serta tidak reliabel mengingat keterampilan yang perlu dikuasai di dalam blok pada umumnya terbatas pada 1 atau 2 keterampilan saja. ${ }^{11}$

Assessment aspek perilaku menggunakan 360 degree feedback juga masih sulit untuk dilaksanakan mengingat jumlah mahasiswa yang sangat banyak yang menyebabkan frekuensi serta kualitas tatap muka antara mahasiswa dengan dosen pengajar 
belum optimal. Banyak aspek penilaian di dalam kuesioner feedback yang ada saat ini menuntut pengisi kuesioner untuk mengenal mahasiswa secara lebih dalam. Dengan demikian, penilaian aspek perilaku ini tidak dapat dilakukan oleh sembarang dosen. Dosen Pembimbing Akademik dianggap sebagai dosen yang cukup mengenal mahasiswa yang mereka bimbing, oleh karena itu ada baiknya penilaian aspek perilaku ini juga melibatkan dosen pembimbing akademik.

Keunggulan dari model pembelajaran di Blok IPK FKUAJ adalah adanya kegiatan mentoring yang terjadwal. Dengan demikian, proses pembelajaran mahasiswa menjadi lebih terbimbing karena mahasiswa memiliki banyak kesempatan untuk melakukan diskusi dan tanya jawab dengan dosen mentor mereka. Selain itu, dosen juga menjadi lebih mengenal mahasiswa di luar jam kuliah/tatap muka sehingga assessment perilaku bisa lebih akurat.

Dalam mengimplementasikan programmatic assessment di dalam Blok IPK, tim blok telah menerapkan beberapa faktor kunci penentu kesuksesan program assessment yang dikemukakan oleh Driessen, et al, ${ }^{12}$ yaitu: memberikan learning value sebanyak mungkin dalam kegiatan assessment, menggunakan assessment yang holistik untuk memberikan informasi kualitatif mengenai performa mahasiswa, mengintegrasikan kegiatan mentoring ke dalam aktivitas pembelajaran mahasiswa, menggunakan model program assessment yang sederhana yang terdiri dari 3 aktivitas (pembelajaran, assessment, dan pendukung), serta mengusahakan agar program assessment tetap 'ramping'. Learning value dari kegiatan assessment didapat apabila terjadi proses feedback yang adekuat antara dosen dan mahasiswa. Proses pemberian feedback di dalam Blok IPK terjadi secara kontinu baik dalam kegiatan pembelajaran (terutama pada sesi working group), kegiatan mentoring, hingga kegiatan assessment (pada saat responsi skills lab, sesi presentasi tugas blok, dll). Selain itu, feedback juga diberikan dalam bentuk tertulis melalui elearning. Holistic assessment dilakukan menggunakan metode 360 degree feedback yaitu dengan mengumpulkan feedback dari 2 dosen mentor (mentor kelompok dan 1 mentor lainnya), 3 orang mahasiswa (yang pernah bekerja sama dengan mahasiswa yang diberi feedback), 1 orang pasien simulasi. Dengan demikian, masing-masing mahasiswa akan menerima 6 buah feedback dari 3 pihak. Self evaluation dilakukan melalui reflective writing yang ditulis oleh mahasiswa sendiri. Hasil dari 360 degree feedback dan reflective writing kemudian dipaparkan kepada mahasiswa dalam sebuah sesi khusus dengan mentor masingmasing. Hanya ada 1 unit yang terlibat dari proses perencanaan hingga evaluasi blok, sehingga dosen pengampu materi, instruktur skills lab maupun tutor pada umumnya merupakan orang yang sama, maka program assessment di blok ini memiliki bentuk yang sangat ramping sehingga memudahkan koordinasi dan implementasi. Hal serupa mungkin akan sulit dilakukan oleh blok-blok lain karena unit/ departemen serta pengajar yang terlibat di dalam blok pada umumnya lebih banyak dan bervariasi.

Hasil evaluasi Blok IPK yang paling menunjukkan perubahan adalah sikap mahasiswa yang mayoritas pada awalnya tidak memilih blok ini, tetapi di akhir blok sungguh merasakan proses belajar yang bermakna (meaningful learning). Sikap ini terbawa oleh mahasiswa dalam karya-karya mereka yang layak digunakan, bahkan siap diproduksi. Sebagai contoh, mahasiswa mampu merancang edukasi personal tentang suatu masalah kesehatan dari awal hingga titik evaluasi. Produk seperti flyer, poster, booklet adalah contoh-contoh produk edukasi personal maupun komunitas yang dapat menjadi bekal mahasiswa menjelang masa klinik ataupun kelak ketika terjun ke masyarakat.

Hasil evaluasi juga menunjukkan aspek keterbukaan mahasiswa terhadap metode pembelajaran yang berorientasi pada mahasiswa (metode SCL), misalnya kegiatan mentoring dan working group. Kedua metode pembelajaran ini terbukti sangat sepadan dengan kebutuhan mahasiswa pada semester yang relatif akhir. Hal tersebut sesuai dengan hasil penelitian Steger-Jagers, et $\mathrm{al}^{13}$ yang menyatakan bahwa tingkat partisipasi (engagement) mahasiswa dalam kegiatan pembelajaran sangat mempengaruhi performa mereka saat menjalani pendidikan kedokteran. Selain itu, kegiatan mentoring dan working group saling berkaitan dan bersifat sebagai pendukung materi pembelajaran sehingga memicu terjadinya overlearning yang membantu meningkatkan penguasaan mahasiswa terhadap topik yang dipelajari. ${ }^{13}$ 


\section{KESIMPULAN}

Kesimpulan yang didapat dari pengalaman menjalankan Blok Elektif Ilmu Pendidikan Kedokteran ini antara lain adalah adanya perubahan paradigma mahasiswa, terutama terasakan dari hasil evaluasi. Dengan memberikan learning value pada setiap kegiatan pembelajaran, mahasiswa akan terpacu untuk belajar secara lebih mendalam dan lebih bermakna, tidak sekedar belajar 'mencari nilai'. ${ }^{12,13}$ Dengan adanya blok elektif ini, mahasiswa dapat dipersiapkan untuk lebih mandiri bila mereka merasa pasti dosen berfungsi maksimal sebagai fasilitator dan mentor. Fasilitator dan mentor bertugas mengarahkan mahasiswa dalam belajar, memberikan feedback, serta membantu mahasiswa untuk merefleksikan tingkat penguasaan materi dan kemajuan belajar mereka. ${ }^{12}$ Aktivitas pendukung yang dilakukan oleh fasilitator dan mentor ini memiliki peranan yang penting dalam menumbuhkan sifat self-directed learning mahasiswa. ${ }^{9}$

Blok IPK dipandang perlu oleh mahasiswa kedokteran. karena itu perlu dipikirkan agar Blok IPK diperkenalkan kepada mahasiswa kedokteran secara menyeluruh, mungkin sebagai satu sessi singkat. Kepada mahasiswa profesi kesehatan, blok ini barangkali dapat diperkenalkan juga. Self-directed learning dapat terjadi bila desain pembelajaran dirancang secara matang dan terstruktur, baik di dalam maupun luar kelas, melalui kegiatan pembelajaran formal maupun informal. ${ }^{13,14}$ Dosen perlu menjalankan fungsinya secara maksimal dalam desain pembelajaran tersebut serta memiliki kerjasama tim yang baik. Blok IPK telah menunjukkan hasil karya tersebut.

\section{UCAPAN TERIMA KASIH}

Penulis ingin mengucapkan terima kasih kepada dr. Nurul I. Hariadi, FAAP, staf Medical Education Unit FKUAJ yang berperan sebagai ketua Blok IPK tahun ajaran 2015/2016 atas seluruh masukan dan bantuannya dalam proses penyusunan artikel ini.

\section{DAFTAR PUSTAKA}

1. Dornan T, Mann K, Scherpbier A, Spencer J (ed). Medical education: theory and practice. Elsevier; 2011.
2. KKI. Standar Pendidikan Profesi Dokter Indonesia. Konsil Kedokteran Indonesia; 2012.

3. Murdoch-Eaton, D. \& Whittle, S. Generic skills in medical education: developing the tools for successful lifelong learning: Generic skills in medical education. Med. Educ. 2012; 46: 120-8.

4. Berkhout, J. J. et al. Exploring the factors influencing clinical students' self-regulated learning. Med. Educ. 2015; 49: 589-600.

5. Frambach, J. M., Driessen, E. W., Chan, L.-C. \& van der Vleuten, C. P. M. Rethinking the globalisation of problem-based learning: how culture challenges self-directed learning: Rethinking the globalisation of PBL. Med. Educ. 2012; 46: 738-47.

6. Stes, A., De Maeyer, S. \& Van Petegem, P. Examining the Cross-Cultural Sensitivity of the Revised TwoFactor Study Process Questionnaire (R-SPQ-2F) and Validation of a Dutch Version. PLoS ONE. 2013; 8: e54099.

7. Khoo, H. E. Implementation of problem-based learning in Asian medical schools and students' perceptions of their experience. Med. Educ. 2003; 37: 401-9.

8. Musick, D. W., McDowell, S. M., Clark, N. \& Salcido, R. Pilot study of a 360-degree assessment instrument for physical medicine \& rehabilitation residency programs. Am. J. Phys. Med. Rehabil. Assoc. Acad. Physiatr. 2003; 82: 394-402.

9. van der Vleuten, C. P. M. et al. A model for programmatic assessment fit for purpose. Med. Teach. 2012; 34: 205-14.

10. Cox, M., Irby, D. M. \& Epstein, R. M. Assessment in Medical Education. N. Engl. J. Med. 2007; 356: 387-96.

11. Khan, K. Z., Ramachandran, S., Gaunt, K. \& Pushkar, P. The Objective Structured Clinical Examination (OSCE): AMEE Guide No. 81. Part I: An historical and theoretical perspective. Med. Teach. 2013; 35: e1437-e46.

12. Driessen, E. W., van Tartwijk, J., Govaerts, M., Teunissen, P. \& van der Vleuten, C. P. M. The use of programmatic assessment in the clinical workplace: A Maastricht case report. Med. Teach. 2012; 34: 226-31.

13. Stegers-Jager, K. M., Cohen-Schotanus, J. \& Themmen, A. P. N. Motivation, learning strategies, participation and medical school performance: Motivation, learning strategies and participation. Med. Educ. 2012; 46: 678-88.

14. Haak, D. C., HilleRisLambers, J., Pitre, E. \& Freeman, S. Increased structure and active learning reduce the achievement gap in introductory biology. Science. 2011; 332: 1213-6. 